\title{
The Crafting scholarly life: Strategies for creating Incubator meaning in academic careers
}

\author{
NED WELLMAN* AND GRETCHEN SPREITZER \\ Stephen M. Ross School of Business, University of Michigan, Ann Arbor, Michigan, U.S.A.
}

\begin{abstract}
Summary Job crafting, which occurs when individuals proactively make changes to their jobs, can be a useful tool for academics seeking more meaningful careers. We suggest changes to the cognitive, task, and relational aspects of academic jobs that can infuse scholarly work with more personal meaning. Copyright (C) 2010 John Wiley \& Sons, Ltd.
\end{abstract}

Keywords: job crafting; meaning; high quality connections

\section{Introduction}

A series of recent articles has reignited a spirited discussion about the meaning of a career in organization studies. These pieces have questioned whether our efforts to date have succeeded in advancing knowledge (Hambrick, 2007), improving the world of practice (Ghoshal, 2005), or helping young scholars advance their careers (Glick, Miller, \& Cardinal, 2007). The widespread attention these articles have garnered suggests that many organizational scholars are interested in making their careers more personally meaningful.

In this Incubator, we use job crafting theory to frame a discussion of how organizational scholars can increase the meaning of their work by changing the way they work. Our foundational assumption is that increasing the personal meaning of academic jobs is valuable and desirable.

Individuals job craft when they make proactive changes to the content and boundaries of their jobs (Wrzesniewski $\&$ Dutton, 2001). Job crafters may engage in three types of crafting: Cognitive crafting, which involves changing task-related boundaries and mindsets; task crafting, which involves changing the content of work-the number, scope and type of job responsibilities; and relational crafting, which involves changing the quality and amount of interaction with others while working. When individuals craft their jobs in these ways, the jobs become more meaningful to them. Although all workers job craft on some level, the recent concerns regarding the meaning of a career in organization studies suggest scholars in our field could benefit from increasing the personal meaningfulness of their work experiences. Therefore, in the remainder of this Incubator we will suggest new ideas of each form of crafting to inspire scholars to build more positive personal meaning into their work lives.

\footnotetext{
* Correspondence to: Ned Wellman, Ross School of Business, Department of Management and Organizations, University of Michigan, 7010 Tappan St., Ann Arbor, MI 48104, U.S.A. E-mail: ewellman@umich.edu
} 


\section{Cognitive Crafting}

Cognitive crafting involves changing task-related boundaries and cognitions. We propose two forms of cognitive crafting that can help organizational scholars derive more meaning from their work: (1) enlarging one's perspective and (2) leveraging more of one's best self. Enlarging one's perspective involves appreciating all of the ways scholarly work can make an impact on others, which in turn infuses the work with more personal meaning. Boyer (1990) suggests scholarship encompasses four separate yet overlapping functions: The scholarship of discovery, which involves the advancement of knowledge through original research and theorizing; the scholarship of integration, which involves making connections across disciplines and paradigms; the scholarship of application, which involves applying knowledge to consequential problems via consulting and service; and the scholarship of teaching, which involves transmitting, transforming, and extending knowledge to students.

We submit that while conducting and publishing research is an important activity in the function of discovery, the other three functions of scholarship can also generate personal meaning. For example, one of our colleagues fulfilled his teaching responsibilities in an experiential learning course by developing a challenging assignment that required students to raise money for the Make-a-Wish foundation. The assignment helped the students learn about teamwork and leadership, and the students also raised over \$35000 for the charity in just two days. By enlarging the cognitive boundaries of his job to include the scholarship of teaching and application, our colleague increased the personal meaningfulness of his work. In doing so, he also created an assignment that was deeply meaningful to his students and received a perfect rating on student evaluations. Our colleague's experience suggests that by enlarging our perspective we can create work that is more meaningful to both ourselves and others.

We suggest that scholars also engage in a second form of cognitive crafting by leveraging more of their best selves. The Reflected Best-Self is an exercise developed to identify a person's special strengths and talents (Roberts, Dutton, Spreitzer, Heaphy, \& Quinn, 2005). In this exercise, individuals use stories from friends, family and colleagues to identify times when they have made a positive contribution to the lives of others. From analyzing these stories, individuals are able to empirically identify their personal strengths. Often people are surprised to learn of the myriad ways they make a difference to others. We believe that academics can benefit from undertaking the Reflected Best-Self exercise. They can also engage in a modified version of the exercise by reflecting on the informal everyday feedback they have received from others regarding what they do well and how they make a positive difference. Scholars can also identify their best selves by considering patterns of peak experiences in their work lives - times when they felt particularly vibrant and impactful at work. For example, some may be particularly gifted facilitators who can uncover the unspoken issues that keep a group from being a team, while others might be strategic thinkers who can envision the next big idea. By understanding their best selves, scholars can find ways to draw on their special strengths and competencies in their everyday work life to make work more enjoyable and meaningful.

\section{Task Crafting}

Task crafting involves changing the content of the work we do. We suggest two forms of task crafting: (1) Focusing on the questions we ask and (2) challenging ourselves to thrive. First, we should ensure that our research is driven by questions that are meaningful personally, practically, and theoretically. For example, several years ago, a number of scholars started to focus on topics related to Positive Organizational Scholarship (POS, Cameron, Dutton, \& Quinn, 2003). They began studying positive deviance and the generative forces that enable thriving in organizational contexts. Shifting the focus of their research questions allowed this group of 
scholars to craft more personal meaning into their work by participating in research projects they perceived as generative and life-giving.

Scholars can also create meaning by crafting more challenge into the content of their jobs. Engaging challenges can create a sense of accomplishment from a job well done. Challenges also energize us and help us learn more from our work. Crafting more challenge into our jobs might involve developing a new teaching module that draws on one's core research findings. For example, one of our colleagues embraced the challenge of developing a computer-based teaching simulation called the Reciprocity Ring which drew directly from his research findings on reciprocity in networks. The simulation also became a mechanism for collecting data from his students and from companies to further fuel his research. In addition, the Reciprocity Ring encouraged students to engage in altruistic actions toward their classmates, which created an altruistic culture in the class that was positively received by the students. Another colleague embraced the challenge of moving into the Dean's office at her business school and creating a new leadership initiative. Rather than simply continuing on her successful trajectory as a researcher, she took the risk of adding a new dimension of administration and leadership into her career path. By embracing challenge, we can increase the quality, meaning, and impact of our work in all of the four functions of scholarship.

\section{Relational Crafting}

Relational crafting involves changing the quality and amount of interaction with others encountered at work. We propose two forms of relational crafting that can increase the meaning of scholarly work: (1) Fostering high quality connections and (2) increasing contact with beneficiaries. High quality connections are relationships characterized by shared goals, shared knowledge, and mutual respect. When individuals are involved in high quality connections, they experience feelings of vitality and aliveness, as well as heightened positive regard for the other party in the connection (Dutton \& Heaphy, 2003). While the most obvious source of high quality connections is one's colleagues (we can choose collaborators that we enjoy spending time with), we can also develop and foster high quality connections with others we come in contact with. Some scholars make a concerted effort to get to know their students - whether sharing a meal with them or organizing travel-study programs which involve extended contact. Wright and Wright $(1999,2002)$ suggest that the participants in our research studies can also be a source of meaning at work (they call this committed to participant research, or CPR). For example, by informing at-risk participants in burnout research about the possible consequences of emotional exhaustion and spending time to discuss coping strategies with them, Wright was able to make an important difference to participants in his research, which in turn made his work more personally meaningful. In fact, by using the CPR approach to fully connect with the participants in his research Wright came to experience his work as a calling, rather than just a job or career (Wrzesniewski, 2003).

Additionally, we should craft our working relationships to put us in more frequent contact with the beneficiaries of our work. When individuals have contact with beneficiaries, they better understand the true meaning of what they do (Grant, 2007). Too often though, scholars have limited contact with beneficiaries. To remedy this, we should make a conscious effort to seek out more interaction with beneficiaries. One powerful way of increasing contact with beneficiaries is by adopting a CPR approach-in which every participant in a research study becomes a potential beneficiary of the researcher's efforts. CPR research involves going beyond a "do no harm" philosophy with the participants in our research. Instead, we can actively think of how we can make a positive difference to our research subjects. Wright, for example, counseled an at-risk participant in his burnout studies to consider a different job that would be less stressful - the participant later reported what a positive effect the change had on her health and marriage (Wright \& Wright, 2002). 


\section{Discussion and Conclusion}

In this Incubator, we suggested ways that scholars can engage in cognitive, task, and relational job crafting to increase the personal meaning of their work. A scholarly job crafting approach to meaningful work presents a number of exciting possibilities, but also some challenges. First, prior research has suggested that jobs present obstacles to aspiring crafters, and that these obstacles may differ by career stage (Berg, Wrzesniewski, \& Dutton, 2010). In academic careers, doctoral students and junior scholars may feel less autonomy to job craft-especially if that crafting does not emphasize the scholarship of discovery. Future research can assess how scholars at different stages effectively craft their work. Second, although career outcomes outside of personal meaning are likely important to many scholars, our discussion of scholarly job crafting focuses primarily on meaning. Third, scholars who enact our suggestions must remain conscious of the impact their job crafting has on others to ensure that in creating more positive meaning for themselves they do not negatively impact others' experiences. Finally, although we have assumed that increasing the personal meaning of academic work is unilaterally positive and desirable, this may not always be true. Employees whose work is overly meaningful may become consumed by their work, at the expense of their outside activities, their relationships with others, and their mental and physical health (e.g., Kreiner, Hollensbe, \& Sheep, 2006). Thus, we should be attentive to warning signs that our work is becoming too meaningful and consuming, and regulate our job crafting accordingly.

In closing, we invite you to think about new ways you might craft your job as an organizational scholar, and then to put those ideas into practice. Start with something small to create some momentum. Job crafting does not have to involve a large commitment like redesigning a course or taking on administrative responsibilities; something as simple as stopping to talk with a former student can significantly increase the feeling that one's job is meaningful and important. As academics we have an unparalleled degree of autonomy in our jobs, and hence unique opportunities to job craft. We challenge you to take advantage of these opportunities and, using this Incubator as scaffolding, construct a career that overflows with positive personal meaning.

\section{Author biographies}

Ned Wellman is a doctoral student in Management and Organizations at the Stephen M. Ross School of Business at the University of Michigan. His research interests include leadership, leadership development, and motivation.

Gretchen M. Spreitzer is professor of Management and Organizations at the Stephen M. Ross School of Business at the University of Michigan. Her research has focused on employee empowerment and leadership development, particularly during times of change. At Michigan, she is part of the Center for Positive Organizational Scholarship where her recent research is on enabling employee thriving at work.

\section{References}

Berg, J. M., Wrzesniewski, A., \& Dutton, J. E. (2010). Perceiving and reacting to challenges in job crafting at different ranks: When proactivity requires adaptivity. Journal of Organizational Behavior, 31, 158-186.

Boyer, E. L. (1990). Scholarship reconsidered: The priorities of the professoriate. Princeton, NJ: Carnegie Foundation for the Advancement of Teaching.

Cameron, K. S., Dutton, J. E., \& Quinn, R. E. (Eds.), (2003). An introduction to positive organizational scholarship. In Positive Organizational Scholarship: Foundations of a new discipline. San Francisco: Berrett-Koehler, 3-13. 
Dutton, J. E., \& Heaphy, E. D. (2003). The power of high-quality connections. In K. S. Cameron, J. E. Dutton, \& R. E. Quinn (Eds.), Positive Organizational Scholarship: Foundations of a new discipline. (pp. 263-278). San Francisco: Berrett-Koehler Publishers, Inc.

Glick, W. H., Miller, C. C., \& Cardinal, L. B. (2007). Making a life in the field of organization science. Journal of Organizational Behavior, 28, 817-835.

Ghoshal, S. (2005). Bad management theories are destroying good management practices. Academy of Management Learning and Education, 4, 75-91.

Grant, A. M. (2007). Relational job design and the motivation to make a prosocial difference. Academy of Management Review, 32, 393-417.

Hambrick, D. C. (2007). The field of management's devotion to theory: Too much of a good thing. Academy of Management Journal, 50, 1346-1352.

Kreiner, G. E., Hollensbe, E. C., \& Sheep, M. L. (2006). Where is the " me" among the" we"? Identity work and the search for optimal balance. Academy of Management Journal, 49, 1031-1057.

Roberts, L. M., Dutton, J. E., Spreitzer, G. M., Heaphy, E. D., \& Quinn, R. E. (2005). Composing the reflected best-self portrait: Building pathways for becoming extraordinary in work organizations. Academy of Management Review, 30, $712-736$.

Wright, T. A., \& Wright, V. P. (1999). Ethical responsibility and the organizational researcher: A committed-to-participant research perspective. Journal of Organizational Behavior, 20, 1107-1112.

Wright, T. A., \& Wright, V. P. (2002). Organizational researcher values, ethical responsibility, and the committed-to-participant research perspective. Journal of Management Inquiry, 11, 173-185.

Wrzesniewski, A. (2003). Finding positive meaning in work. In K. S. Cameron, J. E. Dutton, \& R. E. Quinn (Eds.), Positive Organizational Scholarship: Foundations of a new discipline (pp. 296-308). San Francisco: Berret-Koehler.

Wrzesniewski, A., \& Dutton, J. E. (2001). Crafting a job: Revisioning employees as active crafters of their work. Academy of Management Review, 26, 179-201. 